\title{
On the magnitude of reinforcement and fixed-ratio behavior
}

\author{
GARY F. MEUNIER and CHRISTOPHER STARRATT \\ Ball State University, Muncie, Indiana 47306
}

\begin{abstract}
A large number of studies support the notion that durations of the preratio pause found with fixed-ratio schedules of reinforcement are related inversely to the attractiveness of the reinforcer. An exception to this generalization has recently been reported, however, by Lowe, Davey, and Harzem (1974), who found that magnitude of a liquid reinforcer was positively related to pause durations when all magnitudes were presented within each session. The present data indicate that the Lowe et al. finding may be specific to their experimental design: When performance was studied under steady-state conditions, pause durations were inversely related to reinforcer magnitude.
\end{abstract}

The behavior generated by fixed-ratio (FR) schedules of positive reinforcement typically consists of a pause that immediately follows the reinforcer and a steady rate of responding from the termination of the pause until fulfillment of the ratio requirement (Felton \& Lyon, 1966). The pause, which should be properly termed the preratio pause (PRP) (Mintz, Mourer, \& Gofseyeff, 1967), is sensitive to a host of independent variables, whereas the responding after it seems relatively insensitive to experimental manipulations (e.g., Laursen, 1972). Several studies, for example, suggest that the PRP lengthens with any variable that, for want of a better description, decreases the "attractiveness" of a reinforcer. Thus, increasing the distance to a reinforcer by either increasing the number of responses required (Felton \& Lyon, 1966) or interspersing a delay before delivery of the reinforcer (Morgan, 1972) increases PRP durations, as do also decreasing the subject's level of deprivation (Sidman \& Stebbins, 1959), scheduling a shock during the ratio (Dardano \& Sauerbrunn, 1964), adding a response cost condition to the completion of a ratio (Weiner, 1964), and decreasing the magnitude of reinforcement (Powell, 1969).

An exception to this pattern has been reported, however, by Lowe, Davey, and Harzem (1975, Experiment 3). These investigators reinforced the leverpressing of rats according to a FR 30 schedule with sucrose solutions of varying concentrations. Surprisingly, they found PRP durations to be directly related to sucrose solution concentration, that is, the greater the concentration, the longer the pause. This result is difficult to reconcile with the above findings and provides the motivation for the present study.

One methodological difference between the Lowe

Requests for reprints should be sent to Gary F. Meunier, Department of Psychological Sciences, Ball State University, Muncie, Indiana 47306. This work was partially supported by a grant from the Ball State University Office of Research. et al. (1974) work and others is that the Lowe et al. subjects were presented with all levels of the independent variable in each session. Given that magnitude of reinforcement effects tend to be sensitive to the frequency of presentation of the different conditions (Kramer \& Rilling, 1970), it seems reasonable to suggest that the Lowe et al. results may be specific to the experimental design used in their study. Thus, the present study inquires as to whether the "unconditioned inhibitory effect" of reinforcement noted by Lowe and his co-workers would be found when performance was examined after prolonged exposure to each treatment condition.

\section{METHOD}

\section{Subjects}

The subjects were three Sprague-Dawley-derived male albino rats. Subjects were allowed to reach a free-feeding weight of $300 \mathrm{~g}$ and then were reduced to $80 \%$ of that weight for the duration of the experiment. All three were experimentally naive at the beginning of the study.

\section{Apparatus \\ Data were collected in two sound-insulated operant chambers (LVE/BRS 143-28) with interior dimensions of $26.67 \mathrm{~cm}$ high $x$ $30.50 \mathrm{~cm}$ wide $\times 24.10 \mathrm{~cm}$ deep. The response lever was located on the left side of the front panel about $5.00 \mathrm{~cm}$ above the floor, and reinforcement was a 3-sec presentation of a .01-cc solution of condensed milk (Borden's Eagle Brand). The milk was presented through a small opening in the center of the front panel about $1.25 \mathrm{~cm}$ from the floor and was always signaled by the onset of a brief $(40-\mathrm{msec}) 2.8-\mathrm{kHz}$ tone. All relay programming and recording apparatus were located in an adjacent room. Fresh solutions of the reinforcer were mixed every other day and refrigerated between sessions.}

\section{Procedure}

All subjects were initially hand shaped to leverpress for a $30 \%$ solution of milk; after at least 50 reinforcers had been obtained by leverpressing, the ratio requirement was gradually increased. One subject, R79, was stabilized at FR7, and another, R77, at FR 9. The third subject developed an illness and was removed from the study after being stabilized at FR 6. Perform- 
ance was then studied at solutions (by weight) of $20 \%, 50 \%$, $75 \%$, and $100 \%$ milk; each solution was presented until steadystate behavior was observed. Steady-state behavior was defined as a minimum of five consecutive sessions with no discernible trend in either PRP durations or cumulative records. Order of presentation of the solutions was $30 \%, 75 \%, 100 \%, 50 \%, 75 \%$, and, for R77, $100 \%$. A session consisted of the delivery of 25 reinforcers or the passage of $60 \mathrm{~min}$, and data were collected daily.

\section{RESULTS AND DISCUSSION}

The tendency for pause durations to decrease with increases in sucrose concentration in this study is apparent from examination of Table 1. This table presents the geometric mean concentration of the average PRP from each of the last five sessions at a concentration for each subject. With one exception (R77 at $75 \%$ solution), PRPs lengthened as the concentration of the solution decreased. In accordance with the results of previous investigations (e.g., Meunier \& Ryman, 1974), there was no consistent relationship between the rate of responding after the pause and levels of the independent variable.

The relationship between PRP duration and magnitude of reinforcement for these data is thus opposite to that reported by Lowe et al. (1974). Comparison of the two studies clearly suggests that whether PRP duration varies directly or inversely with reinforcement magnitude is a function of the experimental design utilized. Whether such a qualification must be attached to the aforementioned studies (Dardano \& Saverbraun, 1964; Felton \& Lyon, 1966; Morgan, 1972; Powell, 1969; Sidman \& Stebbins, 1959; Weiner, 1964), which all utilized steady-state designs, remains to be determined.

An interesting incidental observation from these

Table 1

Geometric Mean Preratio Pause (in seconds) as a Function of Reinforcer Concentration

\begin{tabular}{ccrrcc}
\hline & \multicolumn{5}{c}{ Percent Milk } \\
\cline { 2 - 6 } Subject & 30 & \multicolumn{1}{c}{50} & \multicolumn{2}{c}{75} & 100 \\
\hline R77 & 19.8 & 4.5 & 6.1 & $(2.6)$ & 3.8 \\
R79 & 71.4 & 52.8 & 27.1 & $(14.3)$ & 6.1 \\
\hline
\end{tabular}

Note-Numbers in parentheses represent data from a second determination at the solution. data is that pausing was consistently shorter when performance was redetermined at a concentration level. Although this could be taken as an indication of poor experimental control, it is not an uncommon phenomenon (cf. Topping, Johnson, \& McGlynn, 1973, Table 2) and has been noted by other investigators (e.g., Barowsky \& Mintz, 1975, 1978). Unfortunately, an adequate explanation of this finding is not currently available.

\section{REFERENCES}

Barowsky, E. I., \& Mintz, D. E. The effects of time-out locus during fixed-ratio reinforcement. Bulletin of the Psychonomic Society, 1975, 5, 137-140.

Barowsky, E. I., \& Mintz, D. E. The effects of time-out duration during fixed-ratio reinforcement. Bulletin of the Psychonomic Society, 1978, 11, 215-218.

Dardano, J. F., \& Sauerbrunn, D. Selective punishment of tixed-ratio performance. Journal of the Experimental Analysis of Behavior, 1964, 7, 255-260.

Felton, M.. \& Lyon, D. O. The post-reinforcement pause. Journal of the Experimental Analysis of Behavior, 1966, 9. 131-134.

Karmer, T. J., \& Rilling, M. Differential reinforcement of low rates: A selective critique. Psychological Bulletin, 1970, 74. 224-254.

LAURSEN, A. M. Post-reinforcement pauses and response rate of monkeys on a two-hand fixed-ratio schedule. Journal of the Experimental Analysis of Behavior, 1972, 17, 85-94.

Lowe, C. F., Davey, G. C. L., \& Harzem, P. Effects of reinforcement magnitude on interval and ratio schedules. Journal of the Experimental Analysis of Behavior, 1974, 22, 533-560.

Meunier, G. F., \& Ryman, F. Delay of reinforcement in fixedratio behavior. Psychological Reports, 1974, 34, 350.

Mintz, D. E., Mourer, D. J., \& Gofseyoff, M. Sequential effects in fixed-ratio postreinforcement pause duration. Psychonomic Science, 1967, 9. 387-388.

Morgan, M. J. Fixed-ratio performance under conditions of delayed reinforcement. Journal of the Experimental Analysis of Behavior, 1972, 17, 95-98.

Powell, R. W. The effect of reinforcement magnitude upon responding under fixed-ratio schedules. Journal of the Experimental A nalysis of Behavior, 1969, 12, 605-608.

Sidman, M.. \& Stebins, W. C. Satiation effects under fixed-ratio schedules of reinforcement. Journal of Comparative and Physiological Psychology, 1959, 47, 114-116.

Topping, J. S., Johnson, D. L., \& McGlynn, F. D. Effects of delayed reinforcement and FR size on pre-ratio pausing. Psychological Reports, 1973, 32, 1295-1298.

WeINER, H. W. Response cost and fixed-ratio performance. Journal of the Experimental Analysis of Behavior, 1964, 7, 79-81.

(Received for publication February 23, 1979.) 